\title{
LIBERAÇÃO DE MICRONUTRIENTES DE UMA ESCÓRIA APLICADA EM UM ARGISSOLO VERMELHO-AMARELO CULTIVADO COM MUDAS DE GOIABEIRA (Psidium guajava L.) ${ }^{1}$
}

\author{
RENATO DE MELLO PRADO², MÁRCIO CLEBER DE MEDEIROS CORRÊA², ANTÔNIO CARLOS \\ DE OLIVEIRA CINTRA ${ }^{3}$, WILLIAM NATALE ${ }^{4}$, MARCOS ANTÔNIO CAMACHO SILVA²
}

\begin{abstract}
RESUMO - Os micronutrientes são importantes na nutrição das plantas, especialmente em solos tropicais com baixa concentração devido ao intemperismo. Como fonte alternativa de micronutrientes, tem-se a escória, resíduo da indústria de produção de ferro-gusa e aço. Assim, objetivou-se avaliar a escória como fonte de micronutrientes para mudas de goiabeira. O delineamento experimental foi em blocos ao acaso, com cinco repetições. As doses de escória foram aplicadas objetivando elevar em meia, uma vez, uma vez e meia, duas vezes e duas vezes e meia a saturação por bases do solo igual a 70\%, correspondendo a 1,68; 3,36; 5,04; 6,72 e 8,40 g por vaso, além da testemunha sem aplicação. Após 90 dias de incubação da escória com o Argissolo Vermelho-Amarelo, cultivaram-se mudas de goiabeira (cv. Paluma) por 110 dias em vasos com $2,8 \mathrm{dm}^{-3}$ de substrato, em viveiro telado, em Taquaritinga-SP, no período de outubro de 2000 a abril de 2001. A escória promoveu um efeito favorável na reação do solo e na disponibilidades de $\mathrm{Zn}, \mathrm{Cu}, \mathrm{Mn}$ e $\mathrm{B}$ do solo. Houve efeitos quadráticos nas concentrações de $\mathrm{Zn}, \mathrm{Cu}$ e $\mathrm{Mn}$ do solo, que, por sua vez, estiveram associadas às doses de escória superiores a 5,8; 6,3 e 7,5 g por vaso, respectivamente, enquanto, para o B, esse efeito foi linear. A saturação por bases do solo, entre 51 e 55\%, resultou em maior disponibilidade dos micronutrientes $\mathrm{Zn}, \mathrm{Cu}$ e $\mathrm{Mn}$ no solo, ao passo que, para o B, esse valor foi de $65 \%$. Da mesma forma que ocorreu no solo, a aplicação da escória apresentou efeitos quadráticos nos teores de $\mathrm{Zn}$, Cu e Mn da parte aérea e das raízes das mudas de goiabeira, enquanto, para o B, esse efeito foi linear. Concluiu-se, portanto, que a escória se comportou como material corretivo da acidez e como fonte de micronutrientes.
\end{abstract}

Termos para indexação: Psidium guajava frutífera, escória de siderurgia, micronutrientes.

\section{MICRONUTRIENTS RELEASED FROM ONE BASIC SLAG APPLIED A ULTISOL CULTIVATED WITH GUAVA PLANTS (Psidium guajava L.)}

\begin{abstract}
The micronutrients are important in the nutrition of the plants, especially in tropical ground with low concentration of these nutrients. As alternative source of micronutrients, have the basic slag, trash of the siderurgical industry. Thus it was objectified to evaluate the basic slag as source of micronutrients for guava plants. The experimental design was in randomized blocks with five replications. The doses of basic slag had been applied objectifying to raise in zero; half; once, once and half; twice and twice and half the dose to raise $\mathrm{V}=70 \%$, corresponding the $1.68 ; 3.36 ; 5.04 ; 6.72$ and $8.40 \mathrm{~g}$ for pot, besides the witness without application. After 90 days of incubation of the basic slag with substratum (Ultisol), it was cultivated dumb of guava plants (cv. Paluma) per 110 days in pot with $2.8 \mathrm{dm}^{3}$ of substratum. The basic slag promoted a positive effect in the reaction of soil and in the availability of $\mathrm{Zn}, \mathrm{Cu}, \mathrm{Mn}$ and $\mathrm{B}$ in soil. It had quadratic effect in the concentration of $\mathrm{Zn}, \mathrm{Cu}$ and $\mathrm{Mn}$ in soil, that in turn, was associated with the doses of basic slag, superiors the 5.8; 6.3 and $7.5 \mathrm{~g}$ for pot respectively, while that for the B this effect was linear. The basis saturation in the soil between 51 and 55\%, resulted in bigger availability of micronutrients $\mathrm{Zn}, \mathrm{Cu}$ and $\mathrm{Mn}$ in soil, to the pacing that stops the B this value was of $65 \%$. In the same way that occurred in soil, the application of the basic slag presented a quadratic effect in the concentration of $\mathrm{Zn}, \mathrm{Cu}$ and Mn of the top plants and the roots, while that for the B this effect was linear.
\end{abstract}

Index terms: Psidium guajava L., basic slag, guava, micronutrients.

\section{INTRODUÇÃO}

A indústria siderúrgica brasileira produz ferro-gusa e aço e, como resíduo do processo, a escória, com propriedades corretivas da acidez do solo e fonte de alguns nutrientes (Prado \& Fernandes, 2001). O quadro atual do uso agrícola da escória siderúrgica no Brasil é muito restrito, diferentemente de alguns países, como Japão, China e Estados Unidos, nos quais o número de pesquisas e utilização desse material são consideráveis (Prado et al., 2001).

O maior desenvolvimento dessa atividade siderúrgica no Brasil ocorreu na década de 80 , com a expansão do parque industrial nacional. A produção destas siderúrgicas está centrada, basicamente, em aço e ferro-gusa. Cada tonelada desse tipo de

1 (Trabalho 204/2001). Recebido: 20/12/2001. Aceito para publicação: 02/05/2002.

2 Doutorando, Depto de Solos e Adubos, Faculdade de Ciências Agrárias e Veterinárias, UNESP, Via de Acesso Prof. Paulo Donato Castellane, s/n., CEP 14870-000, Jaboticabal-SP, Brasil. E-mail: rmprado@fcav.unesp.br. Bolsista FAPESP.

3 Graduando do curso de Agronomia, Faculdade de Ciências Agrárias e Veterinárias, UNESP - Jaboticabal.

4 Prof. Adjunto, Depto de Solos e Adubos, Faculdade de Ciências Agrárias e Veterinárias, UNESP - Jaboticabal. Bolsista CNPq. E-mail: natale@fcav.unesp.br

Rev. Bras. Frutic., Jaboticabal - SP, v. 24, n. 2, p. 536-542, agosto 2002 
ferro gera em torno de $750 \mathrm{~kg}$ de resíduo, constituído de um silicato de cálcio (Campus Filho, 1981).

Essas escórias apresentam, geralmente, teores elevados de micronutrientes; entretanto, apesar do grande volume gerado pela indústria e de estarem disponíveis, são pouco comercializadas em nosso mercado. Por outro lado, sabe-se que os solos deficientes em micronutrientes são muito comuns no Brasil (Lopes, 1975), especialmente a camada subsuperficial, à qual tem sido usada como substrato para a produção de mudas (Picheth, 1987), pois, devido à ausência de estruturas de propagação de doenças, pragas e ervas daninhas, como a tiririca, enquadra-se dentro das exigências do Ministério da Agricultura para a produção de mudas certificadas (Brasil, 1977).

Desse modo, a aplicação da escória, além de corrigir a acidez do solo, fornece micronutrientes (Amaral et al., 1994), e isso é uma vantagem em relação ao calcário, visto que a escória apresenta, em sua composição, quantidades suficientes para ser considerada fonte de micronutrientes. Esse aspecto ficou comprovado no trabalho de Valadares et al. (1974), que analisaram duas escórias, observando teores superiores de micronutrientes em comparação com dezesseis calcários de diferentes naturezas.

Desta maneira, quando se opta pelo uso do calcário para a neutralização da acidez do solo, os teores já baixos dos micronutrientes, devido à pobreza original do solo, podem diminuir ainda mais pela elevação do $\mathrm{pH}$; entretanto, quando se utiliza a escória como material corretivo, este aspecto da redução da disponibilidade dos micronutrientes no solo é minimizado, devido à presença desses elementos na constituição química da escória.

Na literatura nacional, são poucos os trabalhos que avaliaram as escórias como fontes de micronutrientes. Assim, tornase oportuno o estudo das taxas de liberação de micronutrientes desse resíduo para o solo e, deste, para a planta. Outro aspecto de interesse com vista à preservação ambiental é o manejo adequado da escória, reciclando esse resíduo e obtendo efeito favorável desse material na reação do solo e no fornecimento de micronutrientes.

Existem algumas indicações do benefício dos micronutrientes, especialmente do $\mathrm{Zn}$, no crescimento das plantas e na redução de doenças foliares de goiabeiras adultas (Vasudeva \& Raychaudhuri, 1954; Prasad et al., 1966).

Diante do exposto, o presente trabalho procurou avaliar o efeito da aplicação da escória em um Argissolo Vermelho-Amarelo ácido, na disponibilidade de alguns micronutrientes no solo e no acúmulo desses micronutrientes nas mudas da goiabeira.

\section{MATERIAL E MÉTODOS}

A presente pesquisa foi desenvolvida em um viveiro comercial de mudas, telado, localizado na Rodovia Washington Luiz, km 333,8, no município de Taquaritinga, São Paulo, Brasil, no período de outubro de 2000 a abril de 2001.

O solo utilizado foi um Argissolo Vermelho-Amarelo. A análise química do solo foi realizada de acordo com o método descrito por Raij et al. (1987), apresentando os seguintes valores: $\mathrm{pH}\left(\mathrm{CaCl}_{2}\right) 4,3, \mathrm{M} . \mathrm{O} .=6 \mathrm{~g} \mathrm{dm}^{-3}, \mathrm{H}+\mathrm{Al}=25, \mathrm{Ca}=6, \mathrm{Mg}=3, \mathrm{~K}=0,7$ $\mathrm{e} S \mathrm{SB}=9,7$ todos em $\mathrm{mmol}_{\mathrm{c}} \mathrm{dm}^{-3} \mathrm{e} \mathrm{V}=28 \%, \mathrm{~B}=0,10, \mathrm{Cu}=0,17, \mathrm{Mn}=0,5$, $\mathrm{Zn}=0,3$ todos em $\mathrm{mg} \mathrm{dm}^{-3}$, analisados em extrato de DTPA 0,005 mol L-1 a pH 7,3, conforme o método descrito por Lindsay \& Norwell (1978), exceto para o B, que foi pelo método da água quente (Bataglia \& Raij, 1990).

Utilizou-se escória de aciária, proveniente de uma indústria siderúrgica do município de Piracicaba, São Paulo, Brasil, com as seguintes características químicas: $\mathrm{Cu}=0,4, \mathrm{Zn}=0,9, \mathrm{~B}=$ $0,3, \mathrm{Mn}=24,7 \mathrm{e} \mathrm{Fe}=261,8$ todos $\mathrm{em} \mathrm{g} \mathrm{kg}^{-1}$, analisados em extrato de DTPA, exceto o $\mathrm{B}$, que foi pelo método da água quente, e $\mathrm{CaO}=257 \mathrm{~g} \mathrm{~kg}^{-1} ; \mathrm{MgO}=64 \mathrm{~g} \mathrm{~kg}^{-1} ; \mathrm{PN}$ e PRNT $=61 \%$. A reatividade da escória foi considerada $100 \%$ (material $<0,03 \mathrm{~mm}$ ).

O delineamento experimental foi em blocos ao acaso, com cinco repetições. As doses de escória foram aplicadas objetivando elevar em meia, uma vez, uma vez e meia, duas vezes e duas vezes e meia a saturação por bases do solo a $70 \%$, correspondendo a 1,$68 ; 3,36 ; 5,04 ; 6,72$ e $8,40 \mathrm{~g}$ por vaso de 2,8 $\mathrm{dm}^{-3}$, além da testemunha.

Após a aplicação da escória, o solo ficou incubando por 90 dias e, em seguida, foi realizada uma nova análise química para avaliar as condições químicas do solo, no momento do plantio das mudas (Tabela 1). Esta incubação do solo com a escória, antes do plantio das mudas, teve por objetivo permitir a reação de solubilização da escória e a neutralização da acidez do solo.

Utilizaram-se uma mudas de goiabeira, obtidas a partir de propagação vegetativa de estacas herbáceas de matrizes selecionadas da cv. Paluma. As estacas compostas de um segmento com um par de folhas, correspondendo a um internódio, foram acondicionadas em substrato à base de vermiculita, em câmara de nebulização, por 90 dias, até enraizarem. Após o enraizamento inicial, as estacas foram podadas, ficando com cerca de $10 \mathrm{~cm}$, eliminando-se todas as folhas, obtendo-se assim as mudas.

Após o período de incubação, realizou-se o plantio das mudas de goiabeira, cultivando-as por 110 dias. Ainda por ocasião do plantio, cada unidade experimental recebeu doses de $\mathrm{N}$, $\mathrm{P}, \mathrm{K}$, de 300; 100; $150 \mathrm{mg} \mathrm{dm}^{-3}$, respectivamente, tendo como fontes o sulfato de amônio, o superfosfato triplo e o cloreto de potássio.

Aos 110 dias após o transplante das mudas, realizou-se o corte das plantas, que foram divididas em parte aérea e raiz para a determinação dos micronutrientes, de acordo com a metodologia de Bataglia et al. (1983). Nesse mesmo período (200 dias após a incorporação da escória ao solo), realizou-se nova amostragem de solo dos vasos e novas análises químicas, conforme descrito anteriormente.

\section{RESULTADOS E DISCUSSÃO}

Aos 200 dias após a aplicação da escória, houve efeito significativo e positivo do resíduo na reação do solo, com um aumento quadrático dos valores $\mathrm{pH}\left(\mathrm{Y}=4,24-0,0716 \mathrm{x}+0,0237 \mathrm{x}^{2}\right)$ $\left.\mathrm{R}^{2}=0,97 * *\right)$ e saturação por bases $(\mathrm{V} \%)\left(\mathrm{Y}=24,17+2,357 \mathrm{x}+0,2936 \mathrm{x}^{2}\right.$, $\left.\mathrm{R}^{2}=0,99 * *\right)$. Esses resultados indicam que a escória utilizada comportou-se eficientemente como corretivo da acidez, o que pode ser justificado pelo seu poder de neutralização devido à presença dos ânions silicato. Resultados semelhantes foram obtidos por Prado \& Fernandes (2000;2001).

Para as doses de escória, houve efeito significativo na disponibilidade dos micronutrientes analisados (Figura 1). Ten- 
do em vista que esse material apresenta reação lenta no solo (Prado \& Fernandes, 2000), possivelmente com maior tempo de incorporação (além dos 200 dias), poderia haver maior reação da escória no solo e, conseqüentemente, maior liberação de micronutrientes.

Para a disponibilidade de B, observou-se um efeito linear significativo e positivo, com a aplicação da escória. No caso do $\mathrm{Cu}$, esse efeito foi quadrático, atingindo a maior disponibilidade na dose de 6,3 g por vaso (Figura 1a). Para o Zn e Mn, observouse também efeito quadrático, proporcionando maior disponibilidade nas doses de 5,8 e 7,5 g por vaso, respectivamente (Figura 1b). Esses resultados concordam com os de Amaral et al. (1994), que observaram que a escória de alto forno liberou Mn e Zn em dois Latossolos e, com os de Carter et al. (1951), que observaram incremento de B no solo com a aplicação desse tipo de resíduo.

Como a escória afetou positiva e significativamente a disponibilidade de micronutrientes, a reação do solo e, conseqüentemente, a saturação por bases, o estudo das relações entre essas variáveis mostrou-se oportuno. Pelos resultados obtidos, observa-se uma relação quadrática do valor pH e da saturação por bases (Figura 2) nas concentrações de Mn, Zn, B e Cu disponíveis. De maneira geral, o valor $\mathrm{pH}$ e V\%, a partir de determinados valores, estiveram associados a uma redução da disponibilidade dos micronutrientes. Tal comportamento pode estar relacionado à solubilidade da escória em função do valor $\mathrm{pH}$ do solo. Em condições mais ácidas, haveria maior liberação de micronutrientes da escória, enquanto, com a elevação do valor $\mathrm{pH}$, haveria um equilíbrio na disponibilidade dos micronutrientes. De acordo com Kinniburgh et al. (1976), quando o ambiente tende à neutralidade, a disponibilidade destes elementos diminui, tendo em vista o favorecimento da formação de óxidos dos cátions divalentes e a formação de complexos de superfície (adsorção) desses cátions com sesquióxidos de Fe e de $\mathrm{Al}$ do solo.

Com base nas equações obtidas, pode-se estimar que, em geral, valores pH e de saturação por bases superiores a 5,3 e $65 \%$, respectivamente, acarretaram redução na disponibilidade dos micronutrientes metálicos. Esses valores para o $\mathrm{Zn}, \mathrm{Cu}, \mathrm{Mn}$ e B foram, respectivamente, para o valor $\mathrm{pH}$ e saturação por bases, de 4,9 e 51\%; 5,0 e 53\%; 4,9 e 55\%; 5,3 e 65\%. Portanto, o $\mathrm{B}$ foi o menos afetado, quando comparado com $\mathrm{Zn}, \mathrm{Cu}$ e $\mathrm{Mn}$, em função da reação do solo. Quanto ao boro, Pavan \& Corrêa (1988) encontraram resultados semelhantes, observando aumento considerável na adsorção de B somente em valores pH (água) mais elevados (acima de 6,5). O efeito desses atributos químicos, especialmente do valor $\mathrm{pH}$, na disponibilidade dos micronutrientes metálicos, é amplamente discutido na literatura (Malavolta,1981).

Tendo em vista o aumento da concentração de micronutrientes no solo pela aplicação da escória, avaliaram-se os reflexos desses elementos na parte aérea e nas raízes das

TABELA 1 - Análise química do solo após 90 dias de incubação com a escória, realizada em janeiro de 2001. Taquaritinga-SP

\begin{tabular}{|c|c|c|c|c|c|c|c|c|c|c|c|c|c|c|}
\hline Doses escória & $\begin{array}{c}\mathrm{pH} \\
\mathrm{CaCl}_{2}\end{array}$ & M.O. & $\begin{array}{c}\mathrm{P} \\
\text { (resina) }\end{array}$ & $\mathrm{K}$ & $\mathrm{Ca}$ & $\mathrm{Mg}$ & $\mathrm{H}+\mathrm{Al}$ & SB & $\mathrm{T}$ & $\mathrm{V}$ & B & $\mathrm{Mn}$ & $\mathrm{Cu}$ & $\mathrm{Zn}$ \\
\hline g por vaso & & $\mathrm{g} \mathrm{dm}^{-3}$ & $\mathrm{mg} \mathrm{dm}^{-3}$ & & 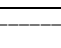 & - & $\mathrm{nol}_{\mathrm{c}} \mathrm{dm}$ & & & $\%$ & - & $-\mathrm{mg}^{-}$ & $\mathrm{Im}^{-3}$ & \\
\hline 0 & 4,2 & 6 & 5 & 1,6 & 7 & 4 & 40 & 12,2 & 51,7 & 24 & 0,14 & 0,4 & 0,17 & 0,6 \\
\hline 1,68 & 4,2 & 6 & 5 & 1,1 & 9 & 4 & 29 & 14,1 & 43,1 & 33 & 0,14 & 0,8 & 0,18 & 0,6 \\
\hline 3,36 & 4,5 & 5 & 4 & 1,8 & 9 & 5 & 24 & 15,8 & 39,8 & 40 & 0,15 & 1,3 & 0,20 & 0,8 \\
\hline 5,04 & 4,8 & 7 & 5 & 1,9 & 10 & 5 & 17 & 16,9 & 33,9 & 50 & 0,17 & 2,1 & 0,22 & 1,5 \\
\hline 6,72 & 5,1 & 6 & 5 & 1,7 & 17 & 5 & 18 & 23,7 & 41,7 & 57 & 0,25 & 2,9 & 0,24 & 1,7 \\
\hline 8,40 & 6,3 & 7 & 6 & 2,4 & 24 & 12 & 16 & 38,4 & 54,4 & 71 & 0,32 & 3,1 & 0,25 & 1,9 \\
\hline
\end{tabular}

(a)

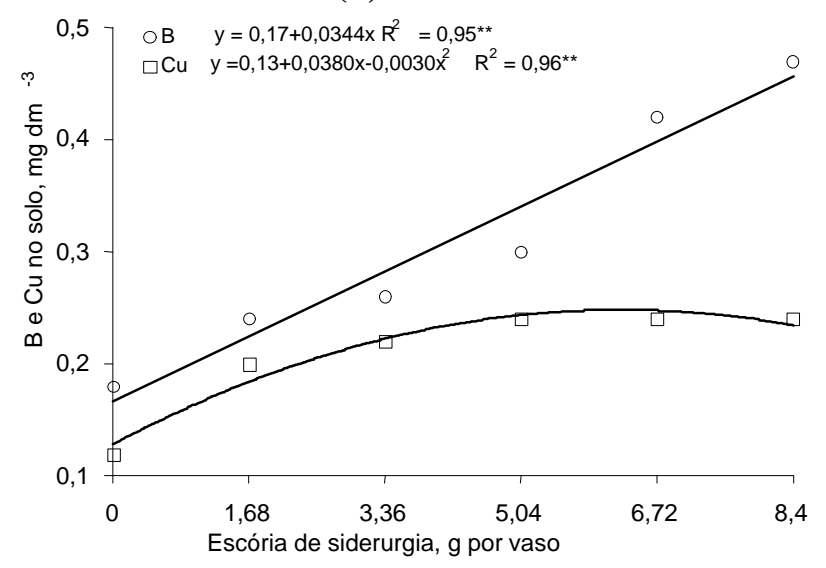

(b)

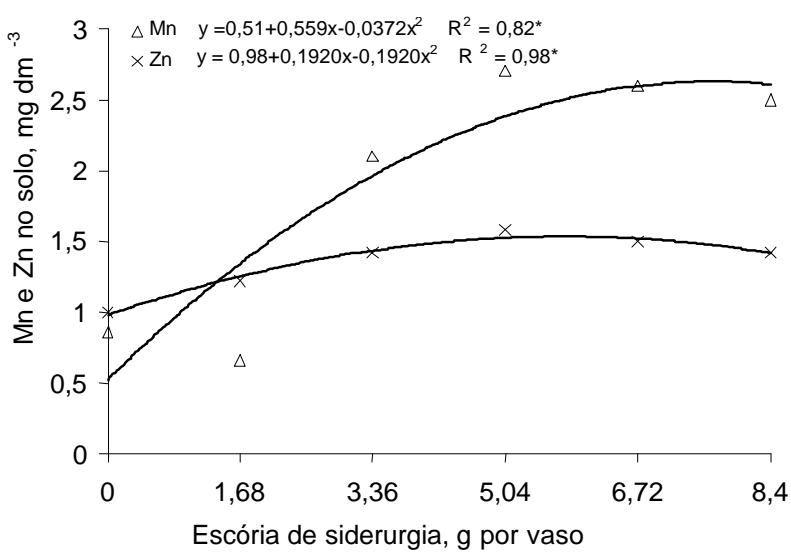

FIGURA 1- Efeito da aplicação de escória na disponibilidade dos micronutrientes B e Cu (a) e Zn e Mn (b) em um Argissolo VermelhoAmarelo. Taquaritinga-SP, 2001. (cada ponto é média de cinco repetições). 
(a)

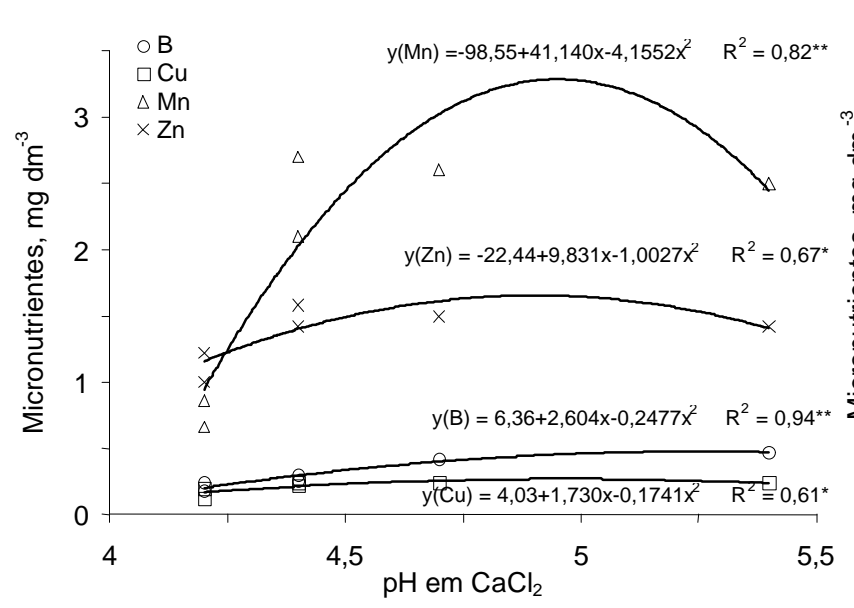

(b)

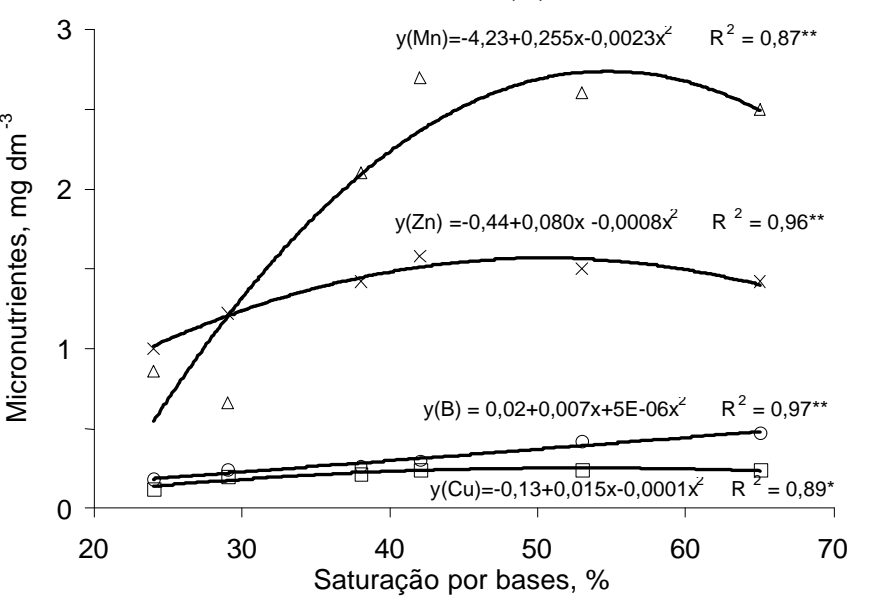

FIGURA 2 - Relação entre o valor pH (a) e a saturação por bases (b) na disponibilidade dos micronutrientes B, Cu, Mn e Zn em um Argissolo Vermelho-Amarelo, submetido à aplicação de escória. Taquaritinga-SP, 2001. (cada ponto é média de cinco repetições).

(a)

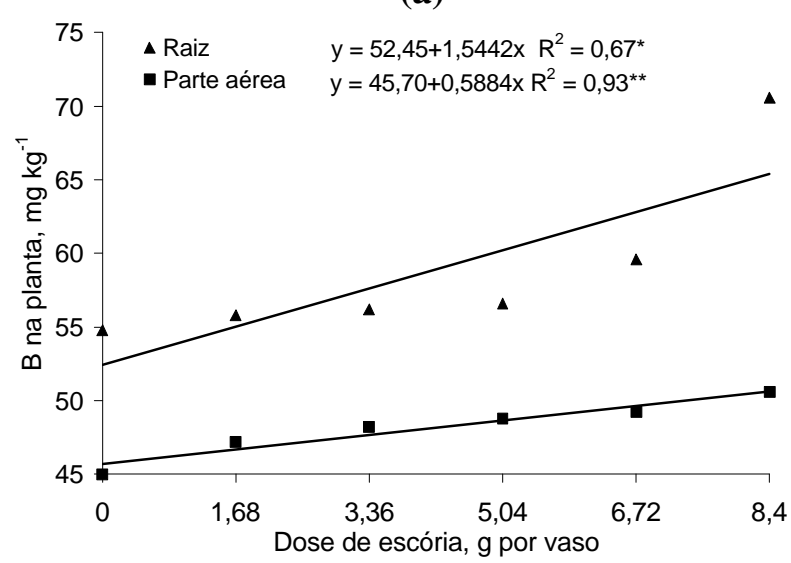

(c)

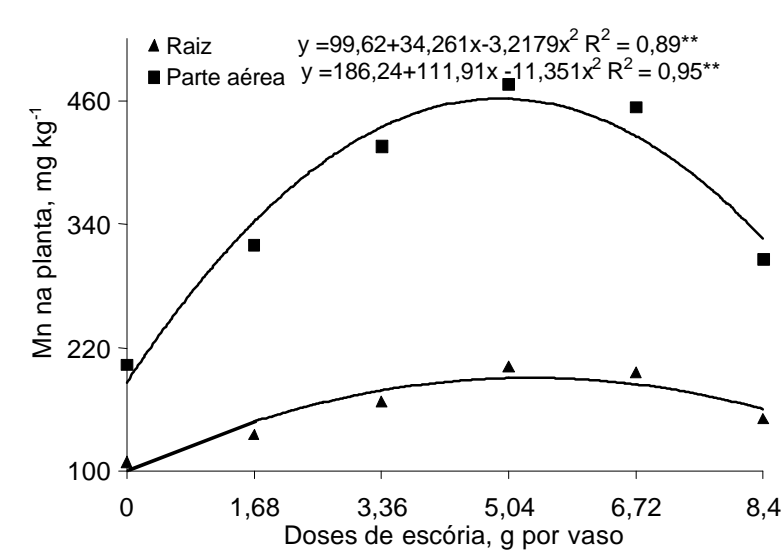

(b)

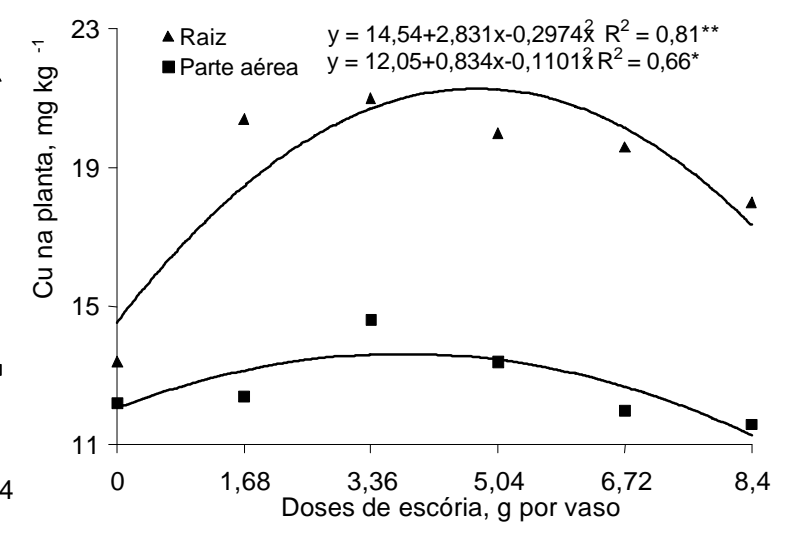

(d)

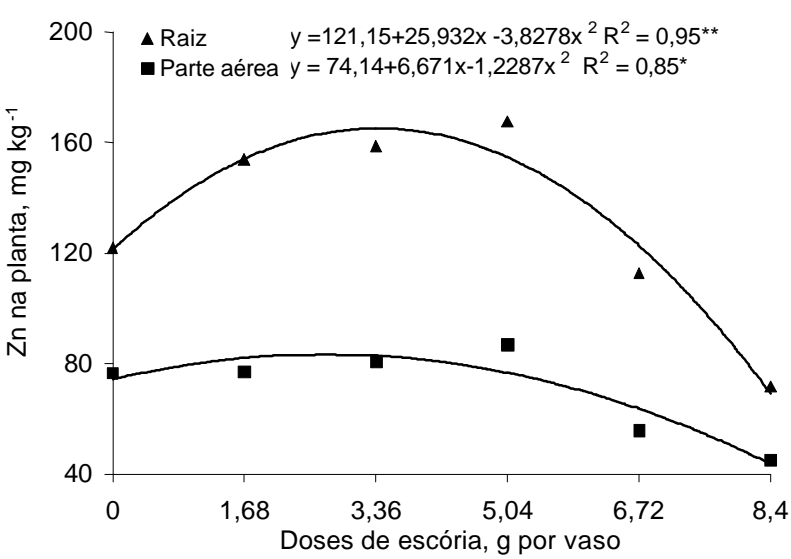

FIGURA 3 - Efeito da aplicação de escória nos teores dos micronutrientes B (a), Cu (b), Mn (c) e Zn (d) na matéria seca da parte aérea e das raízes de mudas de goiabeira cultivadas em um Argissolo Vermelho-Amarelo. Taquaritinga-SP, 2001. (cada ponto é média de cinco repetições). 
(a)

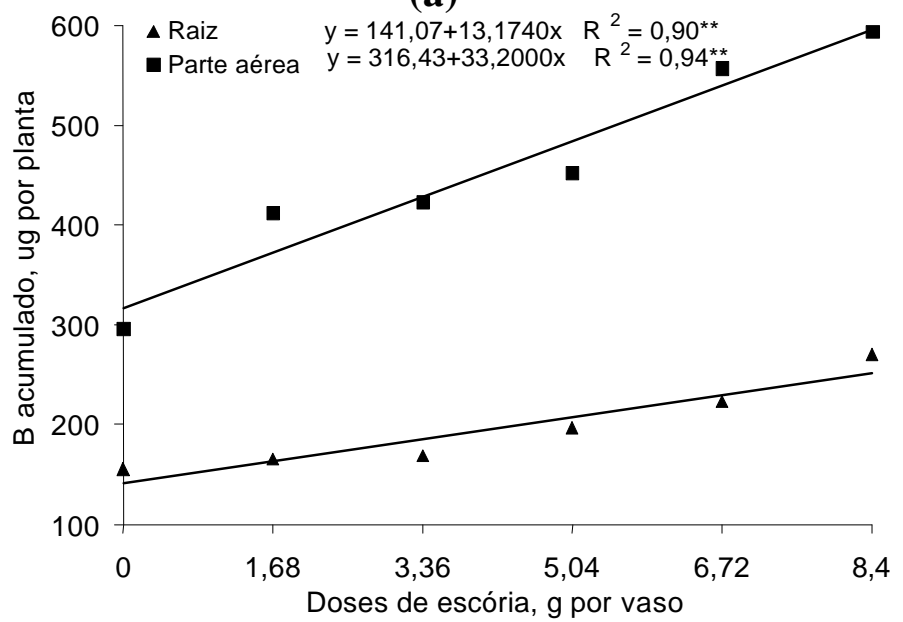

(c)

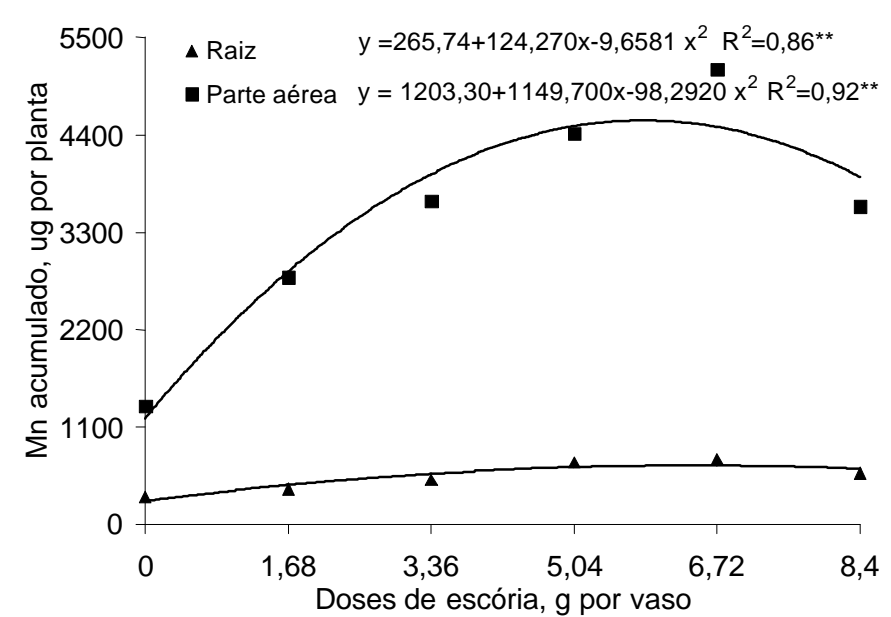

(b)

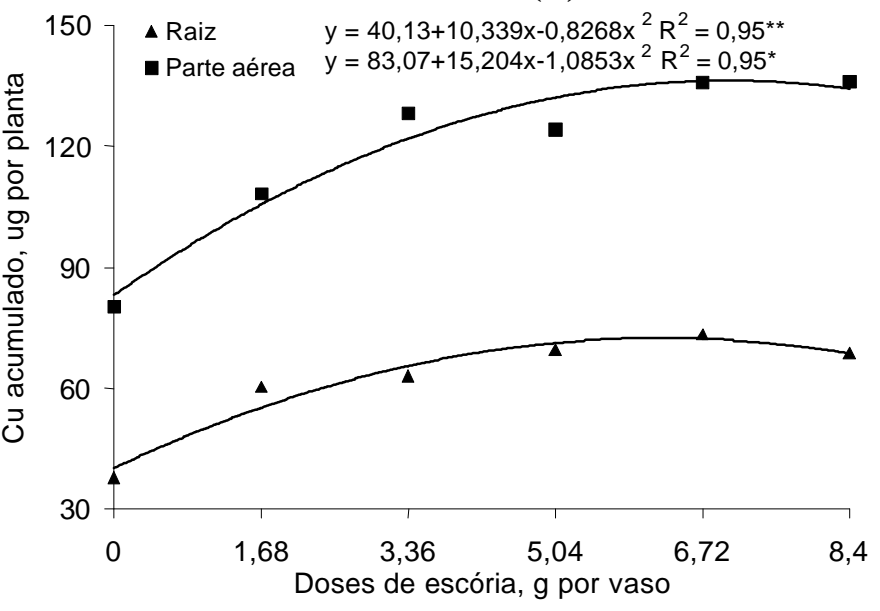

(d)

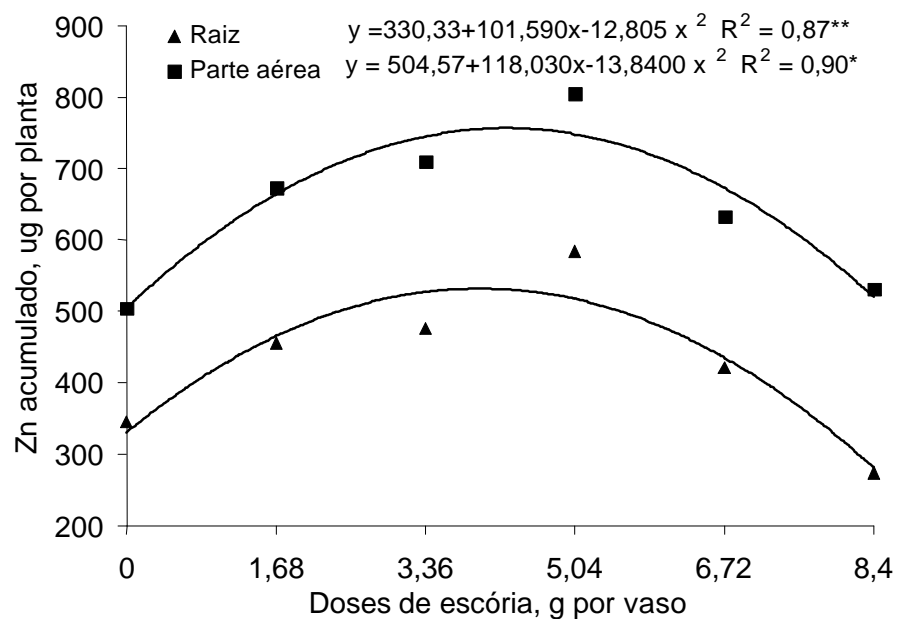

FIGURA 4 - Efeito da aplicação de escória no acúmulo dos micronutrientes B (a), Cu (b), Mn (c) e Zn (d) da parte aérea e das raízes de mudas de goiabeira cultivadas em um Argissolo Vermelho-Amarelo. Taquaritinga-SP, 2001. (cada ponto é média de cinco repetições).

mudas de goiabeira. Houve alteração significativa nos teores (Figura 3) e no acúmulo (Figura 4) dos micronutrientes, com efeito quadrático (exceto para o $\mathrm{B}$, que teve efeito linear), em função do incremento das doses do resíduo. Observaram-se maiores teores de $\mathrm{B}$, $\mathrm{Cu}$ e $\mathrm{Zn}$ nas raízes, ao passo que, para o $\mathrm{Mn}$, ocorreu o inverso, concentrando-se mais na parte aérea (Figura 3). Resultados semelhantes foram obtidos por Salvador et al.(1999), trabalhando com goiabeira em solução nutritiva. Esses autores verificaram que a ordem de exigência das plantas por micronutrientes era: $\mathrm{Mn}>\mathrm{Zn}>\mathrm{B}>\mathrm{Cu}$.

$\mathrm{O}$ incremento de micronutrientes nas plantas, devido à aplicação da escória, foi obtido por Amaral et al. (1994) e Prado et al. (2002) na cultura da alface, por Piau (1995) e Aciolly et al. (2000) na cultura do milho e por Prado et al. (2001) na cultura da cana-de-açúcar.

Observou-se, ainda, que as concentrações de micronutrientes no solo, que estiveram associadas ao maior acúmulo de matéria seca das mudas de goiabeira para $\mathrm{B}, \mathrm{Cu}, \mathrm{Mn}$ e Zn, foram: 0,32; 0,23; 2,3 e 1,2 $\mathrm{mg} \mathrm{dm}^{-3}$ (Figura 5). Segundo Raij et al. (1996), essas concentrações de micronutrientes no solo são consideradas médias (exceto para o $\mathrm{Cu}$, que é considerado baixa). 

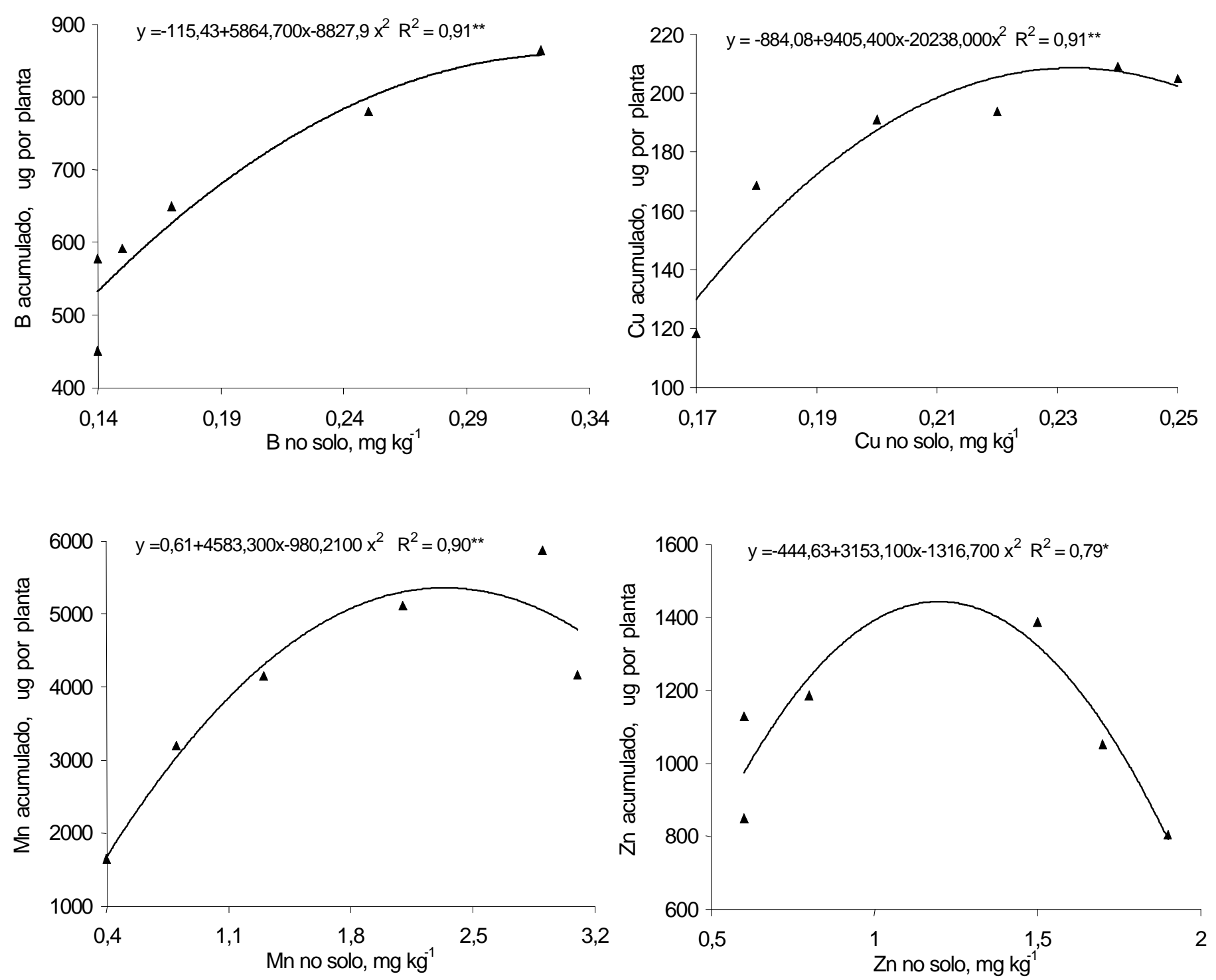

FIGURA 5 - Relação entre a concentração dos micronutrientes B, Cu, Mn e Zn do solo e teores acumulados nas mudas de goiabeira (parte aérea+raiz) cultivadas em um Argissolo Vermelho-Amarelo, submetido à aplicação de escória. Taquaritinga-SP, 2001. (cada ponto é média de cinco repetições).

\section{CONCLUSÕES}

1) A escória propiciou um efeito favorável na reação do solo e no fornecimento e disponibilidade de $\mathrm{Zn}, \mathrm{Cu}, \mathrm{Mn}$ e B.

2) Houve efeitos quadráticos nas concentrações de $\mathrm{Zn}, \mathrm{Cu}$ e $\mathrm{Mn}$ do solo, que, por sua vez, estiveram associadas às doses de escória superiores a 5,8; 6,3 e 7,5 g por vaso, respectivamente, enquanto, para o B, esse efeito foi linear.

3) A saturação por bases do solo entre 51 e $55 \%$ resultou em maior disponibilidade dos micronutrientes metálicos $\mathrm{Zn}, \mathrm{Cu}$ e Mn em um Argissolo Vermelho-Amarelo, ao passo que, para o B, esse valor foi de $65 \%$.

4) Da mesma forma que ocorreu no solo, a aplicação da escória apresentou um efeito quadrático nos teores de $\mathrm{Zn}, \mathrm{Cu}$ e $\mathrm{Mn}$ da parte aérea e das raízes das mudas de goiabeira, enquanto, para o B, esse efeito foi linear.

\section{REFERÊNCIAS BIBLIOGRÁFICAS}

ACCIOLY, A.M.A.; FURTINI NETO, A.E.; MUNIZ, J.A.; FAQUIN, V.; GUEDES, G.A.A. Pó de forno elétrico de siderurgia como fonte de micronutrientes e de contaminantes para plantas de milho. Pesquisa Agropecuária Brasileira, Brasília, v.35,n.7, p.1483-1491, 2000.

AMARAL, A.S.; DEFELIPO, B.V.; COSTA, L.M.; FONTES, M.P.F.. Liberação de $\mathrm{Zn}, \mathrm{Fe}, \mathrm{Mn}$ e $\mathrm{Cd}$ de quatro corretivos da acidez e absorção por alface em dois solos. Pesquisa Agropecuária Brasileira, Brasília, v.29,p.1351-1358,1994.

BATAGLIA, O.C.; FURLANI, A.M.C., TEIXEIRA, J.P.F., FURLANI, P.R., GALLO, J.R.Métodos de análise química de plantas. Campinas: Instituto Agronômico, 1983. 48p. (Boletim Técnico, 78). 
BATAGLIA, O.C., RAIJ, B.van. Eficiência de extratores na determinação de boro em solos. Revista Brasileira de Ciência do Solo,Viçosa,v.14,p.25-31,1990.

BRASIL. Ministério da Agricultura. Portaria no 344 de 01/07/1977.

CAMPUS FILHO, M.P. Processos siderúrgicos. In: Introdução à metalurgia extrativa e siderurgia. Campinas: Fundação de desenvolvimento da Unicamp, 1981.p.122-153.

CARTER, O.R.; COLLIER, B.L., DAVIS, F.L. Blast furnace slags as agricultural liming material. Agronomy Journal, Madison, v.43, p.430-433, 1951.

KINNIBURG, D.G.; JACKSON, M.L., SYERS, J.K. Adsorption of alkaline earth transition, and heavy metal cations by hidrous oxide gels of iron and aluminum. Soil Science Society American Journal, Madison,v.40,p.796-799,1976.

LINDSAY, W.L.; NORWELL, W.A. Development of a DTPA soil test for zinc, iron, manganese and copper. Soil Science Society American Journal, Madison,v.42,p.421-428,1978.

LOPES, A.S. A survey of fertility status of soils under "cerrado" vegetation in Brasil. Raleigh, 1975. 138f. Dissertação (Mestrado)North Carolina State University, Raleigh, 1975.

MALAVOLTA, E. Corretivos cálcicos, magnesianos e calcomagnesianos. In: Manual de química agrícola: adubos e adubação. São Paulo: Agronômica Ceres, 1981.cap.5, p.232-245.

PAVAN, M.A.; CORRÊA, E.A. Reações de equilíbrio solo-boro. Pesquisa Agropecuária Brasileira, Brasília, v.23,p.261269,1988 .

PIAU, W.C. Efeitos de escória em atributos químicos de solos e na cultura do milho (Zea mays L.). 1995. 124f. Tese (Doutorado), Centro de Energia Nuclear na Agricultura, Universidade de São Paulo, Piracicaba, 1995.

PICHETH, J.A.T.F. Viveiros florestais. Londrina: UEL, 1987.29p. (Circular, 52).

PRADO, R.M.; FERNANDES, F.M. Escória e calcário na correção da acidez do solo cultivado com cana-de-açúcar em vaso. Scientia Agricola, Piracicaba,v.57,p.739-744,2000.

PRADO, R.M.; COUTINHO, E.L.M.; ROQUE, C.G.; VILLAR, M.L.P. Avaliação da escória e de calcários como corretivos da acidez do solo no cultivo da alface.Pesquisa Agropecuária Brasileira, Brasília, v.37,p.539-546,2002.

PRADO, R.M.; FERNANDES, F.M; Resposta da cana-de-açúcar à aplicação da escória como corretivo de acidez do solo. Revista Brasileira de Ciência do Solo, Campinas, v.25, n.1,p.201-209, 2001.

PRADO, R.M., FERNANDES, F.M., NATALE, W. Uso agrícola da escória no Brasil: estudos na cultura da cana-de-açúcar. Jaboticabal: FUNEP, 2001. 67p.

PRASAD, N.; MATHUR, R.L.; CHATTRI, I.S. Studies on the control of zinc deficiency of guava in Rajasthan. Indian Journal Agricultural Science, New Delhi,v.36,n.4,p.201-209,1966.

RAIJ, B.van.; CANTARELLA, H.; QUAGGIO, J.A; FURLANI, A.M.C. (Ed.) Recomendações de adubação e calagem para o Estado de São Paulo.2.ed. Campinas: Instituto Agronômico \& Fundação IAC, 1996. p.39. (Boletim Técnico, 100).

RAIJ, B.van., QUAGGIO, J.A.; CANTARELLA, H. Análise química do solo para fins de fertilidade. Campinas: Fundação Cargill,1987.107p.

SALVADOR, J.O.; MOREIRA, A.; MURAOKA, T. Efeito da omissão combinada de $\mathrm{N}, \mathrm{P}, \mathrm{K}$ e $\mathrm{S}$ nos teores foliares de macronutrientes em mudas de goiabeira. Scientia Agricola, Piracicaba,v.56,p.501-507,1999.

VALADARES, J.M.A.S. BATAGLIA, O.C.; FURLANI, P.R. Estudos de materiais calcários usados como corretivos do solo no Estado de São Paulo. Determinação de Mo, Co, Cu, Zn e Fe. Bragantia, Campinas, v.33, p.147-152, 1974.

VASUDEVA, R.S.; RAYCHAUDHURI, S.P. Guava disease in Pushkar Valley and its control. Indian Phytopath, New Delhi,v.7,p.78-81,1954. 